\title{
Percutaneous balloon dilatation of the mitral valve in critically ill young patients with intractable heart failure
}

\author{
J J Patel, M J Munclinger, A S Mitha, N Patel
}

\begin{abstract}
Objective-To assess the outcome of percutaneous balloon dilatation of the mitral valve in critically ill young patients with intractable heart failure.

Design-Retrospective analysis of all such patients presenting over a period of 4 years.

Patients-Of 432 consecutive patients undergoing percutaneous balloon dilatation of the mitral valve, 12 (mean age 29 years) with intractable heart failure were identified. Nine had severe pulmonary oedema and three had pulmonary oedema with severe right heart failure and hypotension. Three patients were pregnant and three required mechanical ventilatory support.
\end{abstract}

Procedure-Percutaneous balloon dilatation of the mitral valve was performed using the Inoue balloon technique. The procedure was shortened by excluding full right study, cardiac output measurement, and left ventriculography. The mitral valve morphology and mitral valve area were determined before and after percutaneous balloon dilatation using cross sectional Doppler echocardiography.

Results-The procedure was technically successful in all patients. The mean (SD) echocardiographic value of the mitral valve area increased from $0.7(0.1)$ to 1.4 $(0.2) \mathrm{cm}^{2}$ with a concomitant reduction in pulmonary artery systolic pressure (Doppler) from 81 (17) to 50 (7) $\mathrm{mm} \mathrm{Hg}$. There was a significant clinical improvement in all patients. The mean (range) fluoroscopy time for the procedure was $6.9(1 \cdot 7-14 \cdot 1) \mathrm{min}$. During follow up (mean 10 months) nine patients were in New York Heart Association (NYHA) functional class $I$, one was in class $I$, one under NYHA elective mitral valve replacement, and one, who refused elective surgery, died suddenly at home.

Conclusion-Percutaneous balloon dilatation of the mitral valve can be performed as a life saving procedure in critically ill patients with mitral stenosis, as even a modest increase in valve area in these patients produces gratifying clinical improvement.

(Br Heart f 1995;73:555-558)

Keywords: mitral stenosis; percutaneous balloon dilatation; pregnancy.
Percutaneous balloon dilatation of the mitral valve has been performed for almost a decade. With emerging knowledge regarding the short- and long-term improvement in haemodynamics and symptoms, certain indications are now apparent. Best results are obtained in patients with pliable non-calcified mitral stenosis. ${ }^{1-6}$ The safety and success of the procedure have also been demonstrated during pregnancy ${ }^{78}$ and in elderly patients who are at high risk for mitral valve surgery as a result of the presence of other illnesses. ${ }^{9}$ Patients with restenosis after previous surgical commissurotomy are also good candidates if the valve morphology is favourable. ${ }^{10}$

Rheumatic mitral stenosis in South Africa, as in other developing countries, takes a rapid and accelerated course and it is not uncommon for younger patients to present with symptoms of heart failure or even acute pulmonary oedema. In these patients attempts are usually made to exclude precipitating factors such as rhythm disturbances, active carditis, systemic or pulmonary infections, anaemia, pregnancy, etc. Despite medical treatment consisting of intravenous diuretics many remain in intractable heart failure. This report describes our results in 12 such predominantly young patients who underwent emergency percutaneous balloon dilatation of the mitral valve.

\section{Patients and methods}

STUDY POPULATION

Of 432 consecutive patients entered in the hospital percutaneous balloon dilatation of the mitral valve registry, we identified a subgroup of ill patients. These were mostly young patients with a mean age of 29 years of whom 10 were female and two male. All were in New York Heart Association (NYHA) class IV. Nine patients had severe pulmonary oedema and three had biventricular failure with hypotension despite medical treatment. Three women were pregnant (30-34 weeks gestation), another had developed intractable pulmonary oedema immediately after delivery, and one other developed cardiac failure after spontaneous abortion at 26 weeks' gestation. All patients were receiving maximum medical treatment consisting of intravenous frusemide (mean dose $140 \mathrm{mg} /$ day) and one of atenolol, verapamil or digoxin. Two patients with hypotension were also on intravenous inotropic treatment. Of nine patients with pulmonary oedema who presented with intense dyspnoea and cough productive of 


\begin{tabular}{|c|c|c|c|c|c|c|}
\hline \multirow[b]{2}{*}{$\begin{array}{l}\text { Patient } \\
\text { No }\end{array}$} & \multirow[b]{2}{*}{$\begin{array}{l}\text { Age } \\
\text { (years) }\end{array}$} & \multirow[b]{2}{*}{ Rhythm } & \multirow[b]{2}{*}{$\begin{array}{l}\text { Echo- } \\
\text { cardiographic } \\
\text { score }\end{array}$} & \multicolumn{3}{|c|}{ Two-dimensional mitral valve area $\left(\mathrm{cm}^{2}\right)$} \\
\hline & & & & $\begin{array}{l}\text { Before } \\
\text { percutaneous } \\
\text { balloon } \\
\text { dilatation }\end{array}$ & $\begin{array}{l}\text { Immediately } \\
\text { after balloon } \\
\text { dilatation }\end{array}$ & $\begin{array}{l}\text { At } \\
\text { follow up* }\end{array}$ \\
\hline $\begin{array}{c}1 \\
2 \\
3 \\
4 \\
5 \\
6 \\
7 \\
8 \\
9 \\
10 \\
- \\
\text { Mean (SD) }\end{array}$ & $\begin{array}{l}22 \\
19 \\
31 \\
17 \\
25 \\
36 \\
50 \\
51 \\
31 \\
19 \\
17 \\
29 \\
29(12)\end{array}$ & $\begin{array}{l}\text { SR } \\
\text { SR } \\
\text { SR } \\
\text { SR } \\
\text { SR } \\
\text { SR } \\
\text { AF } \\
\text { AF } \\
\text { AF } \\
\text { SR } \\
\text { SR } \\
\text { SR }\end{array}$ & $\begin{array}{r}8 \\
7 \\
9 \\
9 \\
9 \\
9 \\
7 \\
10 \\
9 \\
9 \\
6 \\
7 \\
8 \cdot 2(1 \cdot 2)\end{array}$ & $\begin{array}{l}0.8 \\
0.9 \\
0.7 \\
0.6 \\
0.7 \\
0.6 \\
0.5 \\
0.8 \\
0.5 \\
0.7 \\
0.6 \\
0.7 \\
0.7(0.1)\end{array}$ & $\begin{array}{l}1.4 \\
1.8 \\
1.3 \\
1.3 \\
1.4 \\
1.1 \\
1.4 \\
1.3 \\
1.0 \\
1.1 \\
1.7 \\
1.5 \\
1.4(0.2)\end{array}$ & $\begin{array}{l}1 \cdot 5 \\
1.7 \\
1 \cdot 4 \\
1 \cdot 2 \\
1 \cdot 3 \\
1 \cdot 1 \\
1 \cdot 4 \\
-0 \cdot 8 \\
1 \cdot 1 \\
1 \cdot 6 \\
1 \cdot 2 \\
1 \cdot 3(0 \cdot 3)\end{array}$ \\
\hline
\end{tabular}

${ }^{*}$ mean of 10 months after percutaneous balaloon dilatation. SR, sinus rhythm; AF, atrial fibrillation.

profuse bloodstained frothy sputum, two required mechanical ventilation. One enormously obese female who presented with biventricular failure, and a low output state required mechanical ventilation. One patient had undergone surgical closed valvotomy 5 years previously, one had a history of pulmonary tuberculosis as a child and one had a history of asthma. These had not contributed to their present illness.

One of three patients with combined metabolic and respiratory acidosis, who was 34 weeks pregnant, was referred to the cardiac surgeons for mitral valve replacement. She, however, developed decompensation while awaiting surgery and despite resuscitative measures remained hypotensive for about 6-8 h. The fetus died and valve replacement was considered to be a high risk for the mother. Percutaneous balloon dilatation of the mitral valve was undertaken even though the valve morphology was not ideal.

\section{METHODOLOGY}

Percutaneous balloon dilatation of the mitral valve was performed with an Inoue balloon catheter. The standard technique ${ }^{1}$ was modified by omitting right heart study, thermodilution cardiac output measurement, and left ventriculography. After positioning a 7FG pigtail catheter in the ascending aorta at the level of the aortic valve using a right femoral approach, left atrial trans-septal catheterisation was performed by a right femoral venous approach using a Brockenbrough needle and an 8FG Mullins dilator. Diastolic mitral gradient was measured before, in between inflation, and after the procedure using simultaneous left ventricular (pigtail catheter) and left atrial (Inoue catheter) pressures. Mitral regurgitation between inflation was assessed by auscultation and by the extent of regurgitant jet within the left atrium on Doppler mapping. Intravenous heparin (50 units $/ \mathrm{kg}$ ) was administered after left atrial access was achieved. Informed written consent was obtained from all patients or their nearest relative.

The morphology of the mitral valve, mitral valve area, and pulmonary artery systolic pres- sure were determined using two dimensional colour flow Doppler echocardiography. Mitral valve area was calculated using planimetry. The measurements were repeated within $24 \mathrm{~h}$ after the procedure. The mitral valve morphology was scored echocardiographically as previously described. ${ }^{11}$ Transoesophageal echocardiography was not performed in any patients.

Mean values and standard deviations were determined for all variables. Paired Student's $t$ test was used for comparison of two groups of data when applicable.

\section{Results}

The procedure was technically successful in all patients. There were no major complications but two patients developed mild mitral regurgitation. The table shows the Doppler echocardiographic and haemodynamic data in all 12 patients. The mean (SD) echocardiographic morphology score for the mitral valve was $8 \cdot 2(1 \cdot 2)$, confirming the clinical impression that most patients had mitral stenosis that was not ideally suitable for percutaneous balloon dilatation. The mean (SD) mitral valve area increased from $0.7(0 \cdot 1)$ to 1.4 $(0.2) \mathrm{cm}^{2}$ and was associated with a reduction in mitral gradient from $25(6)$ to $9(2) \mathrm{mm} \mathrm{Hg}$ and Doppler derived pulmonary artery systolic pressure from $81(17)$ to $50(7) \mathrm{mm} \mathrm{Hg}$. All results were significant with a $P$ value of $<0.05$.

Three patients with acidosis showed spontaneous correction to normal values within 6-8 h. Ventilatory assistance was withdrawn successfully within minutes after the procedure in one and by the next day in the other two patients. Despite showing clinical improvement right heart failure remained in two patients, one of whom was pregnant with hypotension and the other was one of the three patients who required mechanical ventilatory support. The former had successful mitral valve replacement 4 months after percutaneous balloon dilatation of the mitral valve and the latter who refused surgery died suddenly at home 3 weeks after discharge from hospital. During the follow up period 


\begin{tabular}{|c|c|c|c|c|c|}
\hline \multicolumn{3}{|c|}{ Pulmonary systolic pressure (Doppler) ( $\mathrm{mm} \mathrm{Hg}$ ) } & \multicolumn{2}{|c|}{ Mitral diastolic gradient $(\mathrm{mm} \mathrm{Hg}$ ) } & \multirow[b]{2}{*}{$\begin{array}{l}\text { Fluoroscopy } \\
\text { time (min) }\end{array}$} \\
\hline $\begin{array}{l}\text { Before } \\
\text { percutaneous } \\
\text { balloon } \\
\text { dilatation }\end{array}$ & $\begin{array}{l}\text { Immediately } \\
\text { after balloon } \\
\text { dilatation }\end{array}$ & $\begin{array}{l}\text { At } \\
\text { follow up* }\end{array}$ & $\begin{array}{l}\text { Before } \\
\text { percutaneous } \\
\text { balloon } \\
\text { dilatation }\end{array}$ & $\begin{array}{l}\text { Immediately } \\
\text { after balloon } \\
\text { dilatation }\end{array}$ & \\
\hline 72 & 50 & 40 & 18 & 11 & $4 \cdot 7$ \\
\hline 100 & 45 & 35 & 19 & 9 & $3 \cdot 2$ \\
\hline 110 & 55 & 40 & 35 & 12 & $1 \cdot 7$ \\
\hline 67 & 52 & 42 & 23 & 11 & $6 \cdot 0$ \\
\hline 75 & 42 & 36 & 23 & 7 & $7 \cdot 2$ \\
\hline 80 & 58 & 43 & 33 & 10 & $12 \cdot \overline{2}$ \\
\hline 105 & 55 & 50 & 28 & 10 & $4 \cdot 3$ \\
\hline 50 & 35 & - & 14 & 7 & $14 \cdot 1$ \\
\hline 70 & 45 & 42 & 23 & 10 & $7 \cdot 2$ \\
\hline 77 & 52 & 44 & 25 & 6 & $10 . \overline{9}$ \\
\hline 85 & 50 & 45 & 30 & 9 & 6.6 \\
\hline 70 & 55 & 40 & 26 & 10 & $4 \cdot 9$ \\
\hline $81(17)$ & $50(7)$ & $42(4)$ & $25(6)$ & $9(2)$ & $6 \cdot 9(3 \cdot 7)$ \\
\hline
\end{tabular}

averaging 10 months, nine of the remaining 10 patients were in NYHA class I and one was in class II.

\section{Discussion}

This study in a small number of patients demonstrates the important role that emergency percutaneous balloon dilatation of the mitral valve can play in critically ill patients with tight mitral stenosis in intractable heart failure. There is a paucity of data in the literature regarding emergency mitral valve surgery for the category of young patients who present with severe pulmonary oedema or biventricular failure with hypotension. According to Barlow $^{12}$ the operative mortality for closed surgical valvotomy in this group may be as high as $25 \%$. Most of the patients in this series would have been candidates for closed mitral commissurotomy in the past at our institution. More recently, percutaneous balloon dilatation of the mitral valve has replaced closed surgery. There have been no published data on the mitral valve in such patients who present with intractable heart failure in a moribund state.

Lefevre $e t a l^{9}$ recently reported their experience of percutaneous balloon dilatation of the mitral valve using the double balloon technique in surgical high risk patients. Their study group, however, comprised a totally different category in that they were elderly $(>70$ years) and were high risk as a result of associated disease, involvement of other valves or left ventricular dysfunction. The procedure in their series was technically successful in $82 \%$ of patients. The only other study dealing with percutaneous balloon dilatation of the mitral valve and pulmonary oedema was that of Romero et al. ${ }^{13}$ They used the intra-arterial approach to balloon dilatation of the mitral valve and interestingly seven of their eight patients developed pulmonary oedema during the procedure.

Three important considerations need discussion. First, when dealing with ill patients it is imperative that the technique of percutaneous balloon dilatation of the mitral valve is safe, effective, and quick. Three of our patients were on assisted ventilation and the procedure was performed in a semisupine position in a further three because of intense dyspnoea. There were no technical failures and the mean (range) fluoroscopy time for the procedure was $6 \cdot 9(1 \cdot 7-14 \cdot 1) \mathrm{min}$. Second, there appears to be a poor correlation between the magnitude of the valve area after the procedure and the clinical improvement that occurs. Overall there was a modest increase in valve area. Three patients, despite having a final valve area of $\leqslant 1 \cdot 1 \mathrm{~cm}^{2}$, showed remarkable immediate clinical improvement. Furthermore, there was an unexpectedly high reduction in pulmonary artery pressure immediately after the procedure. Of the two main contributory factors to pulmonary hypertension in patients with mitral stenosis, namely, passive increase of pressure due to increased left atrial pressure and increased pulmonary vascular resistance from vasospasm, the former regresses immediately after balloon dilatation of the mitral valve. The latter decreases over a few days after the procedure. ${ }^{14}$ The degree of relief of mitral obstruction does not correlate with the extent of reduction in pulmonary vascular resistance in mitral valvotomy, ${ }^{15}$ even a small decrease in left atrial pressure causes some decrease in pulmonary vascular resistance. We postulate that any relief of mitral obstruction in these critically ill, haemodynamically unstable patients produces an exaggerated reduction in pulmonary vascular resistance, indirectly indicating the important role of neurohormonal stimulation in producing vasospasm leading to severe pulmonary hypertension.

Third, our results indicate that percutaneous balloon dilatation of the mitral valve can be considered to stabilise the clinical condition of patients with mitral valve morphology not ideal for this procedure before more definitive mitral valve surgery is undertaken in these high surgical risk patients. Although our initial intention was to tide the patient over the critical phase, only one of the 11 surviving patients required surgery at a mean follow up of 10 months.

The Inoue balloon technique enables safe, simple, and quick procedures because of its 
unique features which include a facility for stepwise increase in balloon size, self-positioning, steerability, and the absence of the need for left ventricular guidewire. This study indicates that it is thus ideally suited in ill patients in whom safety, efficacy, and speed are of the utmost importance.

1 Inoue K, Hung JS. Percutaneous transvenous mitral comTopol EJ, ed. Textbook of interventional cardiolog. Philadelphia: WB Saunders, 1990:887-99.

2 Al Zaibag M, Ribeiro PA, Alkasab $S$, Al Fagih MR. Percutaneous double balloon mitral valvotomy for rheumatic mitral stenosis. Lancet 1986;i:757-61.

3 McKay CR, Kawanishi DT, Rahimtoola SH. Catheter balloon valvuloplasty of the mitral valve in adults using balloon valvuloplasty of the mitral valve in adults using

4 Hung JS, Chern MS, Wu J, et al. Short and long term results of catheter balloon percutaneous transvenous results of catheter balloon percutaneous trans

5 Patel JJ, Vythilingum S, Mitha AS. Balloon dilatation of the mitral valve by a single bifoil $(2 \times 19 \mathrm{~mm})$ or trefoil $(3 \times 15 \mathrm{~mm})$ catheter. Br Heart $\mathcal{f} 1990 ; 67: 854-62$.

6 Wilkins GT, Weyman AE, Abascal VM, et at Percutaneous balloon dilatation of the mitral valve: an analysis of echocardiographic variables related to out- come and the mechanism of dilatation. Br Heart $\mathcal{f}$ 1988;60:299-308.

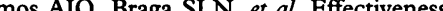
of percutaneous balloon mitral valvotomy during pregnancy. Am ₹ Cardiol 1991;68:930-4.

8 Patel JJ, Mitha AS, Hassen F, et al. Percutaneous balloon mitral valvotomy in pregnant patients with tight pliable mitral valvotomy in pregnant patients with ti
mitral stenosis. Am Heart $f 1993 ; 125: 1106-9$.

9 Lefevre T, Bonan R, Serra A, et al. Percutaneous mitral vefevre $\mathrm{T}$, Bonan $\mathrm{R}$, Serra $\mathrm{A}$, et al. Percutaneous mitral
valvuloplasty in surgical high risk patients. $f \mathrm{Am}$ Coll Cardiol 1991;17:348-54.

10 Davidson CJ, Bashare TM, Mickel M, Davis K. Balloon mitral commissurotomy after previous surgical commissurotomy. Circulation 1992;86:91-9.

11 Wilkins GT, Weyman HE, Abascal VM, Block PC, Palacios IF. Percutaneous balloon dilatation of the mitral valve: an analysis of echocardiographic variables to outcome and the mechanisms of dilatation. Br Heart $\mathcal{F}$ 1988;60:299-308.

12 Barlow JB, ed. Surgical aspects of mitral valve disease. In: Perspective on the mitral valve. Philadelphia: FA Davis, 1987:247-50.

13 Romero M, Melian F, Suarez de Lezo J, Hernandez E, et al. Transarterial mitral valvuloplasty in conditions et al. Transarterial mitral valvuloplasty in conditions of acute puln

14 Dev V, Shrivastava S. Time course of changes in pulmonary vascular resistance and the mechanisms of regression of pulmonary arterial hypertension after balloon mitral valvuloplasty. Am $\mathcal{f}$ Cardiol 1991;67: 439-42.

15 Block PC, Palacios IF. Pulmonary vascular dynamics after percutaneous mitral valvotomy. $\mathcal{F}$ Thorac Cardiovasc Surg $1988 ; 96: 39-43$ 